\title{
Concept and principles of development of a new generation symbiotic preparation
}

\author{
Viktor Popov, and Gayane Svazlyan \\ Kursk Federal Agricultural Research Center", Kursk, Russian Federation, 305021, Karl Marx st., 70B;
}

\begin{abstract}
The article presents the results of the research on the cultivation of B. bifidum and B. subtillis in a high-carbohydrate nutrient medium composed of beet molasses, obtaining metabolites and scientific and practical substantiation of the resulting culture liquid as a biologically active additive. The material of the laboratory studies was sugar beet molasses of 5\%-10\%-15\%-20\%-25\% concentrations. The studies used the probiotic microorganism $B$. bifidum, strain No. 1 and B. subtilis, strain DSM-3242. To obtain bacterial concentrate, a daily culture of microorganisms was used, which was standardized to $1 \times 10^{6} \mathrm{CFU} / \mathrm{cm}^{3}$. The testing process was carried out according to the indicators of the mass fraction of fermented sugars, determined by the calculation method, branch standard OCT 18-395-82. The number of CFU was calculated in the Goryaev chamber using the method of GPhA (General Pharmacopeic Article) 1.7.2.0008.15. The content of amino acids, vitamins, and organic acids in the culture fluid was determined by capillary electrophoresis in the device "Drops". During the cultivation of $B$. bifidum and B. subtillis, a certain metabolic activity of their vitality was found, which is expressed in a decrease in the mass fraction of the amount of fermented sugars in the range of $53.7 \%$ to $23.7 \%$. The hydrogen index is from 6.70 to 3.77 in experimental samples of molasses. The number of B. bifidum and B. subtillis CFUs cultivated on $5 \%$ molasses on the second day reached $7 \times 10^{6} \mathrm{CFU} / \mathrm{cm}^{3}$ and $8.2 \times 10^{6} \mathrm{~cm}^{3}$. In other concentrations, a maximum indicator of the number of microorganisms occurred on the third day and did not exceed 6.6 and $7 \times 10^{6}$ $\mathrm{CFU} / \mathrm{cm}^{3}$. A significant synthesis of metabolites in the form of indispensable and conditionally dispensable amino acids and organic acids was determined. The dynamics of amino acid synthesis is consistent with the amylolytic and enzymatic activity of microorganisms in the molasses culture medium. In this case the level of enzymes is directly dependent on the number of CFU.
\end{abstract}

\section{Introduction}

At present the Russian market of probiotics requires combined preparations that are part of a complex probiotic in which bacterial strains are united by their capability to produce different enzymes, biologically valuable substances in such a way that they will add each other by biological activity. At the same time, studies are being conducted to obtain new multicomponent biologically active preparations that combine a complex of probiotics with prebiotic biologically active components $[1,2,3]$

In the studies $[4,5,6]$ the improvement of these preparations is carried out in the following directions: search for new highly active strains of bifidobacteria and lactic acid bacteria; development of probiotics based on associated microbial cultures; use of auto- and donor strains of endogenous microorganisms for the design of new preparations. The production of antibiotic-resistant strains and the creation of pharmaceutical preparations is based on them to prevent the development of chemotherapeutic disbacteriosis, optimization of production processes, the development of effective and economical nutrient media and medicinal forms of preparations.

In the studies [5,7,8,], it was found that the most promising probiotic microorganisms were representatives of lactobacilli, bifidobacteria, and some spore-forming bacteria from the genus $B$. bacillus. In this connection, we consider it appropriate to note the main biological effects of B. bifidum and B. subtillis.

$B$. bifidum is a species of Gram-positive anaerobic bacteria. They participate in enzymatic processes, perform a vitamin-forming function (synthesis of $\mathrm{B}$ vitamins, vitamin $\mathrm{K}$, folic and nicotinic acids), improve the indicators of protein, lipid and mineral metabolism, as they enhance the hydrolysis of proteins, ferment carbohydrates, saponify fats, dissolve fiber. They stimulate intestinal peristalsis, promote normal intestinal cleansing, promote the synthesis of essential amino acids, better absorption of calcium salts, vitamin $\mathrm{D}$, have

*Corresponding author: ManukyanG@yandex.ru 
anti-anemic, antirachitic and anti-allergic effects, stimulate the lymphoid apparatus. The beneficial properties of bifidobacteria include the ability to effectively absorb lactose, stimulate the immune system, reduce cholesterol in the blood, and have an anticarcinogenic effect $[6,8,9]$.

Along with microorganisms of the genus bifidobacteria, spore-forming bacteria of the genus Bacillus are also of particular interest as probiotic cultures. It was found that bacteria of the genus Bacillus formed bacteriocins that inhibited the growth of pathogenic and opportunistic microorganisms, and also formed substances that neutralized bacterial toxins. Bacteria of the genus Bacillus, when administered orally, activate the nonspecific resistance of animals. Some strains of spore-forming aerobic bacteria induce the production of endogenous interferon in the animal body not only when administered parenterally, but also when administered orally, which has both antiviral and antibacterial effects. These processes underlie the mechanism of therapeutic action of preparations from bacillus cultures $[10,11,12]$.

Pathogenic aerobic bacteria of the genus Bacillus have an antagonistic activity of a wide range of pathogenic and opportunistic microorganisms, produce a number of enzymes that decompose starch, pectins, cellulose, fats, proteins, and regulate and stimulate the digestive processes. The inclusion of spore probiotics in feed contributes to an increase in the efficiency of feed use and animal productivity $[12,13,14]$.

Both Bifidobacterium bifidum and Bacillus subtillis are very demanding on the composition of the nutrient medium. The ability of spore probiotics to synthesize a complex of enzymes makes it possible to cultivate them on plant substrates, enriching them with protein, vitamins and other biologically active substances.

As a high-carbohydrate nutrient medium, the medium based on beet molasses is most suitable for the cultivation of Bifidobacterium bifidum and Bacillus subtillis.

The purpose of the research is the concept and principles of the development of symbiotic preparations in the cultivation of probiotic microorganisms in a nutrient medium based on beet molasses.

To achieve this goal, the following tasks were solved:

- determination of the variability of the dynamics of CFU in the nutrient medium and of the metabolite composition;

- substantiation of the results of the study of EPS (experimental probiotic suspension) as a biologically active dietary supplement.

\section{Materials and methods}

The research was carried out in the laboratory "Agrobiotechnologies" of Kursk Federal Agricultural Research Center. The research material was sugar beet molasses of 5\%-10-15-25\% concentration. For the fermentation of molasses, probiotic microorganisms $B$. bifidum, strain No. 1, and B. subtillis, strain DSM-3242, were used. To obtain the bacterial concentrate, a daily culture of microorganisms was used, which was standardized to $1 \times 10^{6} \mathrm{CFU} / \mathrm{cm}^{3}$. After standardization, the bacterial culture was added to a molasses culture medium and cultured for 8-10 days in a KBCG-100/250 thermostat at $(37 \pm 1)^{\circ} \mathrm{C}$. During the experimental period, the amount of $\mathrm{CFU}$ in the culture fluid was taken into account when counting in the Goryaev chamber using a Levenhuk 740T, M1400 Plus microscope. The fermentation testing process was carried out by the indicators of the mass fraction of fermentable sugars, determined by the calculation method of the branch standard OST 18-395-82. The content of amino acids, vitamins, and organic acids in the culture fluid was determined by capillary electrophoresis. To determine amylotic activity, a Loury-Bertony medium was used into which a $1 \%$ starch solution was added, the proteolytic activity was carried out by hydrolysis with $1 \%$ casein solutions by proteases according to the methods (Mitra Patall, Bertrand, T. F., et al.).

\section{Results of the research}

The chemical composition of molasses is soluble saccharides, mainly sucrose, as well as a small amount of fructose, glucose and raffinose, minerals (about 10\% of crude ash) and non-protein nitrogen compounds. Molasses contains about 35 to $45 \%$ of sugar. The saccharides contained in it are assimilated by pigs and ruminants by more than $90 \%$. The amount of energy depends on the amount of sugar. Molasses is a byproduct of sugar production in the form of brown syrup. In $1 \mathrm{~kg}$ of it there are $116 \mathrm{~g}$ of crude ash, $135 \mathrm{~g}$ of crude protein, $3 \mathrm{~g}$ of crude fat and $746 \mathrm{~g}$ of nitrogen-free extracts (NFE), $652 \mathrm{~g}$ of sugar, $0.5 \mathrm{~g}$ of phosphorus, 2.5 $\mathrm{g}$ of calcium, $54 \mathrm{~g}$ of potassium, $7.6 \mathrm{~g}$ of sodium, $0.2 \mathrm{~g}$ of magnesium, $0 \mathrm{~g}$ of starch. In the chemical composition of molasses, $79 \%$ of dry matter is singled out [Potthast C. et al.].

It should be noted that the parameters of beet molasses allow it to be used as a nutrient medium for the cultivation of probiotic microorganisms. Sugar beet molasses is taken as the basis of the nutrient medium due to the sufficient content of carbohydrate components, crude protein and minerals.

The conducted studies allow us to note the variability of the dynamics of colony-forming units (CFU $10^{6}$ ) of a probiotic microorganism in relation to the nutrient medium, which was molasses in different concentrations.

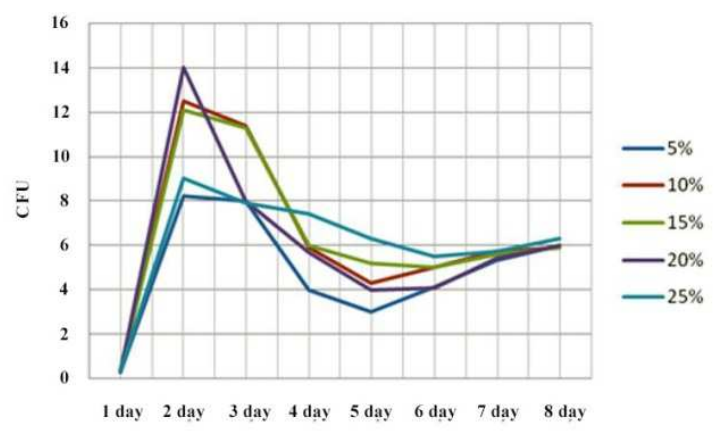

Figure 1. Variability of the dynamics of Bifidobacterium bifidum $\mathrm{CFU}$ in relation to the molasses concentration 


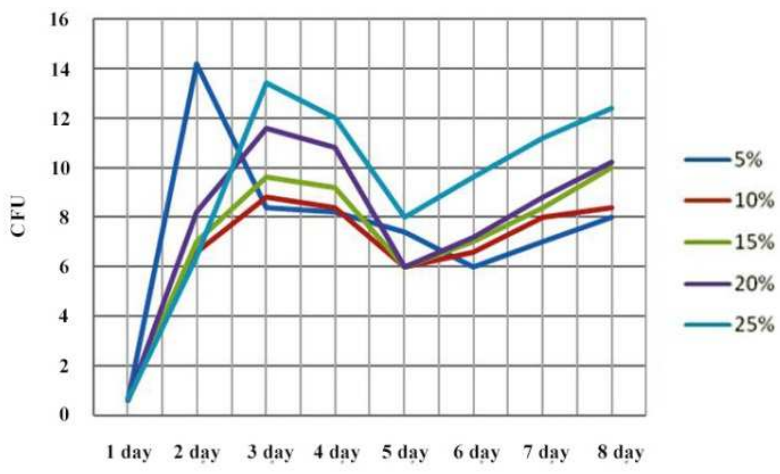

Figure 2. Variability of the dynamics of Bacillus subtilis $\mathrm{CFU}$ in relation to the molasses concentration

Figures 1 and 2 show the growth of the number of microorganisms of probiotic cultures. The number of $B$. bifidum and B. subtillis CFUs cultivated on 5\% molasses on the second day reached $7 \times 10^{6} \mathrm{CFU} / \mathrm{cm}^{3}$ and $8.2 \times 10^{6}$ $\mathrm{CFU} / \mathrm{cm}^{3}$. In other concentrations, the maximum indicator of the number of microorganisms occurred on the third day and did not exceed 6.6 and $7 \times 10^{6}$ $\mathrm{CFU} / \mathrm{cm}^{3}$. It should be assumed that the $5 \%$ concentration of molasses allows B. bifidum and Bacillus subtillis to multiply more actively due to the nutrition of easily fermented sugars during the first 2 to 3 days. On the fifth day the number decreases to minimum values in all molasses concentrations and is 3 to $4 \times 10^{6} \mathrm{CFU} / \mathrm{cm}^{3}$. On days $5^{\text {th }}$ to $6^{\text {th }}$, there is a repeated increase in the number, which may be due to the transition of bifidobacteria to feed on sugars that are more complex. So on the eighth day the maximum number of microorganisms was observed in $25 \%$-concentrated molasses: $6.5 \times 10^{6} \mathrm{CFU} / \mathrm{cm}^{3}$; and the minimum in $5 \%$ concentrated molasses: $4 \times 10^{6} \mathrm{CFU} / \mathrm{cm}^{3}$. However, it is most appropriate to use $5 \%$-concentrated molasses, since $B$. subtillis allows one to achieve the maximum number of $\mathrm{CFU}$ of probiotic microorganisms for a minimum period of cultivation. At the same time, the 25\% molasses concentration allows one to maintain the number of microorganisms in the range of 3.6 to 6.6 $\mathrm{CFU} / \mathrm{cm}^{3}$ for up to 8 days. At the same time, it was found that the maximum number on the eighth day was in B. bifidum $\left(6.5 \times 10^{6} \mathrm{CFU} / \mathrm{cm}^{3}\right)$.

During the cultivation of Bifidobacterium bifidum and Bacillus subtillis, a certain metabolic activity of their vital activity was established, which is expressed in a decrease in the mass fraction of the amount of fermented sugars in the range of $53.7 \%$ to $23.7 \%$, the hydrogen index from 6.70 to 3.77 in experimental samples of molasses (Table 1).

It should be noted that with an increase in the number of CFU of probiotic cultures, metabolites in the form of amino acids, organic acids and vitamins are released into the culture fluid (Table 2).

Attention is drawn to the fact of a significant increase in the synthesis of indispensable amino acids in relation to the control. It should be noted that the amino acids are converted into molasses from beets by 50 to $60 \%$. The studies found a significant excess of lysine 26 times, phenylalanine 14 times, leucine+isoleucine 6.4 times, and other indispensable and conditionally dispensable amino acids, which indicates a significant activity of probiotic microorganisms in the nutrient medium. At the same time, it is necessary to take into account the importance of individual protein-forming acids for the animal body and the resulting complex of amino acids in protein metabolism.

Table 1. Characteristics of the molasses culture medium, $\mathrm{M} \pm \mathrm{m}$

\begin{tabular}{|l|c|c|c|}
\hline $\begin{array}{l}\text { Indicator } \\
\text { Name }\end{array}$ & $\begin{array}{l}\text { Molasses } \\
5 \%, \\
\text { Control }\end{array}$ & $\begin{array}{l}\text { B. bifidum } \\
\text { Molasses 5\% }\end{array}$ & $\begin{array}{l}\text { B. subtillis } \\
\text { Molasses 5\% }\end{array}$ \\
\hline $\begin{array}{l}\text { Mass fraction } \\
\text { of dry } \\
\text { substances, \% }\end{array}$ & $5,56 \pm 0,14$ & $3,46 \pm 0,71$ & $4,87 \pm 0,61$ \\
\hline $\begin{array}{l}\text { Mass fraction } \\
\text { of crude } \\
\text { protein, g / }\end{array}$ & $5.35 \pm 0.25$ & $5.60 \pm 1.04$ & $5.70 \pm 0.37$ \\
\hline $\begin{array}{l}\text { Hydrogen } \\
\text { index, pH }\end{array}$ & $6.70 \pm 0.91$ & $3.77 \pm 0.56$ & $3.82 \pm 0.12$ \\
\hline $\begin{array}{l}\text { Mass fraction } \\
\text { of the amount } \\
\text { of fermented } \\
\text { sugars, \% }\end{array}$ & $53.7 \pm 0.21$ & $23.7 \pm 1.02$ & $21,4 \pm 0,23$ \\
\hline
\end{tabular}

Table 2. Metabolite composition of the culture fluid

\begin{tabular}{|c|c|c|c|}
\hline Indicator Name & $\begin{array}{l}\text { Molasse } \\
\text { s 5\% } \\
\text { Control }\end{array}$ & $\begin{array}{l}\text { Molasses } 5 \% \\
\text { Cultured } \\
\text { Bifidobacteriu } \\
m \text { bifidum }\end{array}$ & $\begin{array}{l}\text { Molasse } \\
\mathrm{s} \quad 5 \% \\
\text { Culture } \\
\mathrm{d} \\
\text { Bacillus } \\
\text { subtillis }\end{array}$ \\
\hline \multicolumn{4}{|c|}{ Mass fraction of proteinogenic amino acids } \\
\hline Arginine & 18.3 & 10.5 & 29.4 \\
\hline Lysine & 0.62 & 27.9 & - \\
\hline Tyrosine & 0.44 & 29.1 & - \\
\hline Phenylalanine & 0.31 & 14.8 & - \\
\hline Histidine & 5.4 & 6.1 & 2.4 \\
\hline $\begin{array}{l}\text { Leucine+Isoleuci } \\
\text { ne }\end{array}$ & 14.9 & 90.1 & - \\
\hline Methionine & 2.10 & 14.5 & - \\
\hline Valine & 3.5 & 36.4 & - \\
\hline Proline & 2.4 & 83.9 & 3.1 \\
\hline Threonine & 1.5 & 163.1 & 1.8 \\
\hline Serine & 4.8 & 26.5 & 1.6 \\
\hline Alanine & 1.5 & 224.8 & 1.2 \\
\hline Glycine & 1.8 & 33.0 & 1.7 \\
\hline \multicolumn{4}{|c|}{ Mass fraction of organic acids } \\
\hline Oxalic acid & 7.1 & 4.7 & 6.8 \\
\hline Succinic acid & 13.7 & 563.3 & 588.8 \\
\hline Acetic acid & 453.4 & 1086 & 329.3 \\
\hline \multicolumn{4}{|c|}{ Mass fraction of water-soluble vitamins } \\
\hline $\begin{array}{l}\text { Thiamine } \\
\text { Chloride } \\
\text { Hydrochloride } \\
\text { (B1) }\end{array}$ & 4.9 & 5.5 & 4.6 \\
\hline Riboflavin (B2) & 26.0 & 4.4 & 29.9 \\
\hline $\begin{array}{l}\text { Pantothenic acid } \\
\text { calcium salt (B3) }\end{array}$ & 42.0 & 37.3 & 54.8 \\
\hline
\end{tabular}

Indicators of organic acids produced by probiotic microorganisms have a high degree of difference in 
relation to the control. The qualitative composition of organic acids makes it possible to predict their positive effect on the animal body. At the same time, the oxalic acid content in the test sample is slightly lower in relation to the control by $1.5 \%$. The acetic acid content is 2.4 times higher. The indicator of succinic acid in the experimental sample in relation to the control is increased 41.1 times. It should be assumed that the nutrient medium from molasses and the specificity of the metabolism of Bifidobacterium bifidum are not adequate in relation to organic acids. However, high levels of succinic and acetic acids indicate a high degree of anaerobic oxidation processes in the cultured microorganism.

The metabolites of cultured probiotic microorganisms from the vitamin group are mainly represented by group "B". Their variability both between the experimental samples and in relation to the control should be noted. The metabolic activity of probiotic microorganisms associated with the synthesis of amino acids and vitamins is consistent with their enzyme activity in the nutrient medium (Fig. 3, 4).

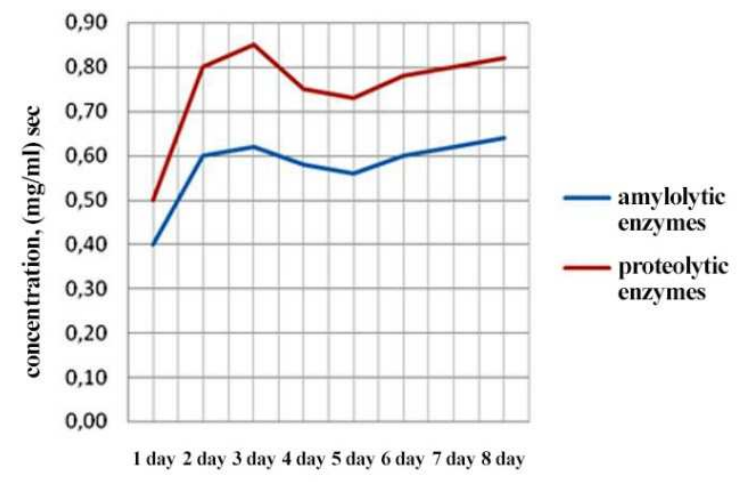

Figure 3. Concentration of enzymes produced by $B$. bifidum in $5 \%$ molasses

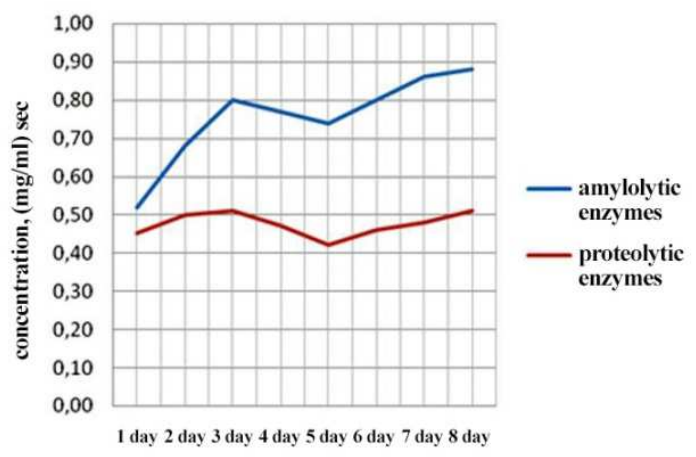

Fig. 4. Concentration of enzymes produced by $B$. subtillis in 5\% molasses

When cultivating Bifidum in 5\% molasses, the indicators of proteolytic enzymes dominate in comparison with amylolytic ones. In this case, the level of enzymes directly depends on the amount of CFU. Characteristic increases in proteolytic and amylolytic enzymes are observed on the 2 nd and 3rd day, in the range of $0.85-0.62 \mathrm{mg} / \mathrm{ml} / \mathrm{sec}$, respectively, from the 4th day indicators decrease and reach values in the range of $0.73-0.56 \mathrm{mg} / \mathrm{ml} / \mathrm{sec}$. The repeated increase in the activity is observed from the 6th day and reaches 0.78 $0.60 \mathrm{mg} / \mathrm{ml} / \mathrm{sec}$. During cultivation of B. subtillis in $5 \%$ molasses, the reverse activity is observed. As can be seen from Figure $4 \mathrm{~B}$. subtillis is characterized by an increase in amylolytic enzymes in the limits of $0.8-0.88$ $\mathrm{mg} / \mathrm{ml} / \mathrm{sec}$, while the indicators of proteolytic enzymes were $0.5-0.51 \mathrm{mg} / \mathrm{ml} / \mathrm{sec}$.

Thus, during the cultivation of Bifidobacterium bifidum and Bacillus subtillis, a certain metabolic activity of their vital activity was established, it was expressed in a decrease in the mass fraction of the amount of fermented sugars in the range of $53.7 \%$ to $23.7 \%$, the hydrogen index from 6.70 to 3.77 in experimental samples of molasses. At the same time, the conducted studies allow to note the variability of the dynamics of colony-forming units (CFU $10^{6}$ ) of a probiotic microorganism in relation to the nutrient medium, which was molasses in different concentrations. It should be noted that there is a positive tendency to increase the synthesis of proteinogenic amino acids in relation to the control in a nutrient medium of 5\% molasses. The amount of enzymes produced in EPS directly depends on the probiotic culture. The obtained metabolites in different probiotic cultures have different variability, which is associated with the multicomponent nature of molasses. The obtained experimental probiotic suspension is characterized by a certain biologically active composition and can be used for further development as a biologically active additive for the correction of metabolism in animals.

\section{Discussion}

The development of biologically active additives based on probiotic microorganisms provides for the production of their metabolites in the process of cultivation on various nutrient media. Grain culture media is the most optimal variant for obtaining metabolites. In our studies a nutrient medium based on sugar beet molasses was used. The results of the conducted studies on the cultivation of probiotic microorganisms are consistent with the direction of the research and the indicators of other authors $[4,6,2]$.

During the cultivation of Bifidobacterium bifidum and Bacillus subtillis, a certain metabolic activity of their vital activity was established, which is expressed in a decrease in the mass fraction of the amount of fermented sugars in the range of $53.7 \%$ to $23.7 \%$, the hydrogen index from 6.70 to 3.77 in experimental samples of molasses.

It should be assumed that the 5\% concentration of molasses allows B. bifidum and Bacillus subtillis to multiply more actively due to the nutrition with easily fermented sugars during the first 2 to 3 days. On the fifth day, the number decreases to the minimum values in all molasses concentrations and is 3 to $4 \times 10^{6} \mathrm{CFU} / \mathrm{cm}^{3}$. On the $5^{\text {th }}$ to $6^{\text {th }}$ day, there is a repeated increase in the number, which may be due to the transition of bifidobacteria to a diet of more complex sugars, while on the eighth day the maximum number of microorganisms was observed in $25 \%$-concentrated molasses - $6.5 \times 10^{6}$ 
$\mathrm{CFU} / \mathrm{cm}^{3}$, and the minimum was in $5 \%$ molasses $-4 \mathrm{x}$ $10^{6} \mathrm{CFU} / \mathrm{cm}^{3}$.

The quantitative and qualitative composition of the metabolites in the form of proteinogenic amino acids and the probiotic microorganism $B$. subtilis. and B. bifidum allows us to characterize the experimental probiotic suspension as a liquid biologically active additive. The dynamics of amino acid synthesis is consistent with the amylolytic and enzyme activity of microorganisms in the molasses culture medium. In this case the level of enzymes directly depends on the amount of CFU. The increase in proteolytic and amylolytic enzymes was observed on the 2nd and 3rd days, in the range of 0.85$0.62 \mathrm{mg} / \mathrm{ml} / \mathrm{sec}$, respectively, from the 4th day; the indicators decrease and reach values in the range of $0.73-$ $0.56 \mathrm{mg} / \mathrm{ml} / \mathrm{sec}$. The repeated increase in activity is observed from the $6^{\text {th }}$ day and reaches up to $0.78-0.60$ $\mathrm{mg} / \mathrm{ml} / \mathrm{sec}$. During cultivation of B. subtilis in 5\% molasses the reverse activity is observed. When cultivating $B$. subtilis, an increase in amylolytic enzymes was found in the range of $0.8-0.88 \mathrm{mg} / \mathrm{ml} / \mathrm{sec}$, while the indicators of proteolytic enzymes were $0.5-0.51$ $\mathrm{mg} / \mathrm{ml} / \mathrm{sec}$. The research is consistent with the works $[4,13,20]$. It should be noted that the development of preparations and biologically active additives based on B. subtilis metabiotics is carried out in Russia and Germany only in medical practice (preparations Bactistatin and Hilak-forte), research on the development and use of biologically active additives based on metabiotics in animal husbandry and veterinary medicine is at the initial stage of study $[13,18,19]$.

\section{Conclusion}

Thus, the scientific concept in the research is an integrated approach to solving the problem of creating a biologically active additive. The main scientific principles of the probiotic concept for the development of new-generation symbiotic preparations are determined:

- study of the cultivation aspects of the metabolite probiotic Bacillus subtilis, strain DSM-3242 IV, and $B$. bifidum, strain No. 1 in appropriate nutrient media from beet molasses;

- determination of the quantitative and qualitative composition of metabolites in the probiotic producer;

- scientific and practical substantiation of the qualitative and quantitative composition of the experimental probiotic suspension as a biologically active additive.

Under cultivation of B.bifidum optimal results were obtained on a $5 \%$ nutrient medium from molasses, the variability of the mass fraction of the amount of fermented sugars was established in the range of 53.7 to $23.7 \%$, the hydrogen index from 6.70 to 3.77 , the maximum number of $\mathrm{CFU}$ was $6.5 \times 10^{6} \mathrm{CFU} / \mathrm{cm}^{3}$ on the eighth day. A significant synthesis of metabolites in the form of indispensable and conditionally dispensable amino acids and organic acids found. The dynamics of amino acid synthesis is consistent with the amylolytic and enzyme activity of microorganisms in the molasses culture medium. The level of enzymes directly depends on the amount of CFU.

The results of the research are aimed at the development of new approaches and the creation of new symbiotic preparations with their subsequent use in animal husbandry, the creation of biologically active feed additives for normalizing the microbiota of the gastrointestinal tract in animals, stimulating nonspecific immunity, and the development of a new generation of metabiotic preparations.

\section{References}

1. I. V. Anikienko, O. P. Ilyina, L. N. Karelina, I. I. Silkin Vestnik IrGSHA, 84, 126-135, (2018).

2. S. Lebeer, P. A. Bron, M. L. Marco, J-P. Van Pijkeren, O’Conell, M. Motherway, C. Hill, B. Pot, S. Roos, T. Klaenhammer Current Opinion in Biotechnology 49, 217 - 223, (2018)

3. I. M. Magomedaliev, R. V. Nekrasov, M.G. Chabaev, V.V. Javakhia, E.V. Glagoleva, M.I. Kartashov Agrarian Science, 1, 22-26, (2020).

4. V. Kh. Melikidi, D. G. Tyurina, D. G. Selivanov, N. I. Novikova Poultry Farming. 09-10, 45-476 (2019).

5. R. Patel, H.L. DuPont Clin. Infect. Dis. 60(2), 108-121, (2015). doi: 10.1093/cid/civ177.

6. A. Singh, V. Vishwakarma, B. Singhal Advances in Bioscience and Biotechnology, 9, 147-189, (2018). DOI: 10.4236/abb.2018.94012

7. S.M. Cutting Food Microbiol. 28 (2), 214-220, (2011) doi: 10.1016/j.fm.2010.03.007.

8. M. Roselli, R. Pieper, C. Rogel-Gaillard, H. Smidt, C. Lauridsen Animal Feed Science and Technology. 233, 104-119, (2017) DOI:10.1016/ j.anifeedsci.2017.07.011.

9. B. Sánchez, S. Delgado, A. Blanco-Míquez, A. Lourenço, M. Guimond, A. Margolles Mol. Nutr. Food Res. 61(1) (2017) doi: 10.1002/mnfr.201600240.

10. Ch. Hansen International Pig Topics. 33(2), 6-7 (2018)

11. L. Lin, J. Zhang BMC Immunol. 18(2), 2-25, (2017) doi: 10.1186/s12865-016-0187-3.

12. K. Bai, Q. Huang, J. He, L. Zhang, T. Wang Poultry Science. 96 (1), 74-82, (2017). DOI: 10.3382/ps/pew246.

13. V.S. Popov, N.V. Vorobyeva, G.A. Svazlyan, N.M. Naumov, O.A. Gryaznova Systematic Reviews in Pharmacy. 11(9), 813-817, (2020) DOI:10.18411/srp.2020.9.115.1.

14. Y. Uyeno, S. Shigemori, T. Shigemori Microles environ. 30 (2), 126-132, (2015).

15. P. Mitra, R. Chakraverty, A. L. Chandra Brazilian Journal of Science Research (55), 439-442, (1994).

16. T.F. Bertrand, T. Frederic, N. Robert Production and Partial Characterization of a thermostable amylase from Ascomycetes yeast strain isolated from starchy soil. (McGraw-Hill Inc., New York. 2004). 
17. C. Potthast et al. Sugar Industry, 36 (10), 663-669 (2011)

18. B. A. Shenderov, Medical microbiological ecology and functional nutrition. (Moscow: Grant, 2001)

19. M. D. Ardatskaya, L.G. Stolyarov, V.E. Arkhipov, Difficult patient, 6-7, 35-39 (2017).

20. Kh-T. Nguyen, D-H. Truong, S. Team S., Lee, H. Razafindralambo, F. Delving Int J Mol Sci., 17(6), 867, (2016) doi: 10.3390/ijms17060867. 